Silvertown, J., P. M. Biss and J. Freeland (2009): Community genetics: resource addition has opposing effects on genetic and species diversity in a 150-year experiment. Ecology Letters 12, 165-170.

VELLEND, M. (2003): Island biogeography of genes and species. The American Naturalist 162, 358-365.

VELLEND, M. (2004): Parallel effects of land-use history on species diversity and genetic diversity of forest herbs. Ecology 85, 3043-3055.

VELlend, M. (2005): Species diversity and genetic diversity: parallel processes and correlated patterns. The American Naturalist 166, 199-215.

Vellend, M. and M. A. Geber (2005): Connections between species diversity and genetic diversity. Ecology Letters 8, 767-781.

VELLEND, M. and J. L. ORROCK (2009): Genetic and ecological models of diversity: lessons across disciplines. In: Losos, J. B., Ricklefs, R. E. (eds.). The Theory of Island
Biogeography Revisited. Princeton University Press, Princeton, pp. 439-461.

Vos, P., R. Hogers, M. Bleeker, M. Reijans, T. van De Lee, M. Hornes, J. Frijters, J. Peleman, M. Kuiper and M. ZABEAU (1995): AFLP: a new technique for DNA fingerprinting. Nucleic Acids Research 23, 4407-4414.

Wehenkel, Chr., F. Bergmann and H.-R. Gregorius (2006): Is there a trade-off between species diversity and genetic diversity in forest tree communities? Plant Ecology 185, 151-161.

Wehenkel, Chr., F. Bergmann and H.-R. Gregorius (2007): Genotype-species interactions in neighbourhoods of forest tree communities. Silvae Genetica 56, 1101-110.

WEI, X. and M. JIANG (2012): Contrasting relationships between species diversity and genetic diversity in natural and disturbed forest tree communities. New Phytologist 193, 779-786.

\title{
Genetic Variation and Correlation among Resin Yield, Growth, and Morphologic Traits of Pinus massoniana
}

\author{
By QinghuA LiU ${ }^{1)}$, Zhichun Zhou ${ }^{1), *)}$, HuinuA FAN ${ }^{2)}$ and Yurong LiU ${ }^{2)}$
}

(Received 25 ${ }^{\text {th }}$ April 2012)

\begin{abstract}
In breeding programs, the variations and relationships among main traits need to be understood to develop selection and breeding strategies. Resin is considered as one of most important non-timber production of $P$. massoniana which can privides terpenes used in the chemical industry. The present study assessed the genetic variations in growth, morphologic traits, and resin yield, as well as the phenotypic and genetic correlations between these traits of 45 half-sib families of eight-year-old Pinus massoniana trees. All traits show highly significant family effects. The individual heritability for diameter at breast height $(\mathrm{DBH})$ was the highest $\left(h^{2}{ }_{i}=0.55\right)$. Heritabilities for resin yield, tree height, crown depth, and the height to the live crown were slightly lower than $\mathrm{DBH}$, ranging from 0.32 to 0.45 . The other traits were under weak genetic control and heritabilities ranged from 0.17 to 0.20 . All growth and morphologic traits were significantly correlated genetically with resin yield. Number of living branches had the highest genetic correlation with resin yield $\left(r_{g}=0.99\right)$, followed by DBH and number of living whorls $\left(r_{g}=0.73\right.$ and 0.70$)$. Only a moderate positive genetic cor-

1) Research Institute of Subtropical Forestry, The Chinese Academy of Forestry, 73 Daqiao Road, Fuyang 311400, People's Republic of China.

2) Fujian Academy of Forestry Sciences, 35 Shangchiqiao Road, Fuzhou 350012, People's Republic of China.

*) Corresponding author: Zhichun ZHoU. Tel: +86-571-63315867, Fax: +86-571-63310041. E-Mail: liuqinghua642@163.com
\end{abstract}

relation with resin yield was found with the other traits $\left(r_{g}=0.47-0.57\right)$, except for height under the living branches $\left(r_{g}=-0.45\right)$. The results of this study indicate that both resin yield and growth can be improved simultaneously in the next generation. Of the traits assessed $\mathrm{DBH}$ was the optimum trait for indirectly selecting high-yielding resin trees.

Key words: resin yield; growth; morphologic traits; heritability; genetic correlation; Pinus massoniana.

\section{Introduction}

Pine resin is an important non-timber secondary forest product. It produces turpentine (monoterpenes and sesquiterpenes) and rosin (diterpenes). These compounds are used widely in solvents, cleaning agents for varnishes and paints, production of flavor and fragrances in the pharmaceutical and food industry, perfumes, synthetic rubber, disinfectants, coatings, printing ink resins, and waterproofing materials (COPPEN and Hone, 1995; LeE et al., 2001; KELKAR et al., 2006).

China is the leading producer of rosin in the world. From 2002 to 2007, China produced 50 tons to 60 tons of rosin per year, about one third of the global rosin supply, with $90 \%$ of the rosin coming from Pinus massoniana. P. massoniana is an important timber and resin tree species in South China. Fujian, Guangdong, Guangxi, Hu'nan, and Zhejiang Provinces are the main yielding resin regions of $P$. massoniana. In recent years, the resin 
price has risen annually. For example, the resin purchased from forest farmers has an average price of 15 Yuan (about 2.35 dollars) per kilogram in 2011. It is more profitable for farmers than harvesting trees for timber. Rosin producers also believe that the rosin of $P$. massoniana is better than that of $P$. elliotii when producing hydrogenated and disproportionated rosin (CHEN et al., 2004). However, one of the most critical problems that forest farmers face is the possible shortage of resin resulting from the depletion of natural $P$. massoniana forests and the low average resin yield of $P$. massoniana plantations. To maintain the annual resin yield, larger plantation areas have had to be tapped, decreasing the efficiency of resin collection.

The resin yielding ability varies among and within pine species (TADESSE, 2001). Resin yield is a highly heritable trait, and important genetic gains can be obtained from the selection of high resin yielders (MERGEN et al., 1955). For example, McReynolds and Gansel (1985) estimated gains of about $64 \%$ over unselected progeny after one generation of selection in a tree improvement program designed specifically to increase the gum yields of slash pine (for naval stores products). SQUILLACE and BENGSTON (1961) have estimated that the heritability of gum yield in slash pine is quite high (about 55\%). A general method for increasing resin yield is to genetically improve resin yield and develop resin pine plantations. In China, genetic improvement to increase resin yield was initiated in the mid to the late 1980s. Most of the attention has been devoted to selecting high resin yielding trees by phenotypic performance from natural forests and unimproved plantations. Variations in resin yielding ability exist within and among populations of $P$. massoniana, and many superior provenances, families, and clones for further studies on genetic improvement have been selected (WENG et al., 2010; LIU, 2006; LI, 2008). In contrast, little is known and characterised about the genetic contribution of phenotypic variation to resin yield in $P$. massoniana.

For coping with unstable market price for resin, it is usually expected to improve resin yield combining with timber. So the genetic correlations between resin yield and growth traits have major implications for developing selection and breeding strategies. Previous studies on the relationship of resin yield and growth are inconsistent. Some studies have proposed there is no correlation between resin yield and growth traits, although high-yield resin trees have slightly smaller heights and slightly larger diameters (TADESSE et al., 2001). How ever, most studies have supported the opinion that positive correlation exsit between resin yield and growth traits, and larger diameters could yield more resin than their smaller counterparts in pine species (ROBERDS, 2003; RoDRIGUES, 2008). In addition, it is more convinient to predict whether a tree has high resin yield, if we found one or several morphologic traits closely related to resin yield.

In the present study, the main aims were to determine the genetic and phenotypic variations in juvenile resin yield and growth traits, and the correlations of genetic and phenotypic correlations with growth, morphologic traits, and resin yield.

\section{Materials and Methods}

\subsection{Sampling}

The study material consisted of open-pollinated families of 44 plus trees randomly selected in a first generation seed orchard. All these plus trees were selected within the Fujian provenance for high resin yield and the seed orchard was established by grafting in 1984 to 1985. A unimproved seed source was also included in the progeny test as control, which is commercial seed commonly used in Laizhou. The progeny test site is located south of the Laizhou forest farm in Nanping City of Fujian $\left(117^{\circ} 57^{\prime} \mathrm{E}, 26^{\circ} 38^{\prime} \mathrm{N}\right.$, altitude $=306 \mathrm{~m}$ to $\left.352 \mathrm{~m}\right)$, with a mean annual rainfall of $1669 \mathrm{~mm}$ and a mean annual temperature of $19.3^{\circ} \mathrm{C}$. The soil type is red earth with medium fertility. The tested site have a randomized complete block design with 5 blocks, 5-tree row plots and $2.0 \mathrm{~m} \times 3.0 \mathrm{~m}$ spacing between trees. No particular silvicultural treatment was performed, and resin was not tapped prior to the experiments. Suppressed trees were thinned aged five leaving between three and four trees per plot.

Three trees per plot were chosen randomly for the present study, except the trees harboring physical or mechanical damage, and are showing any signs of plagues and diseases. Resin yield was measured using the bark streak method of wounding for resin tapping. After removing the outer bark at breast height using a sharp hatchet, a streak was made in the bark-shaved face. The streak was $1 \mathrm{~mm}$ to $2 \mathrm{~mm}$ high and $3 \mathrm{~mm}$ to $4 \mathrm{~mm}$ deep into the xylem, had a side gutter angle of $45^{\circ}$ and tapping load rate of $25 \%$. Resin from each wound was funneled into open plastic bags attached to the base of the wounds and weighed after $24 \mathrm{~h} \pm 1 \mathrm{~h}$. Rewounding was carried out every 15 days throughout the experimental period from May to October. All streaks were parallel and had the same height and depth. No stimulant to induce resin bleeding was applied. The resin yield was calculated as the yield of the individual pine tree per day per $10 \mathrm{~cm}$ streak length in grams.

Growth traits including/diameter at breast height $(\mathrm{DBH})$, total height and morphologic traits, including height under live crown, crown width and crown depth, bark thickness, number of living branches and number of living whorls, were measured simultaneously.

\subsection{Statistical analysis}

All traits were analyzed by the following linear model:

$$
Y_{i j k}=\mu+B_{i}+F_{j}+B \times F_{i j}+\varepsilon_{i j k}
$$

where $Y$ represents the phenotypic individual observation, $\mu$ is the overall mean, $B_{i}$ is the effect of the $i$ th block ( $i=1$ to 4 ), $F_{j}$ is the effect of the $j$ th family ( $j=1$ to $45), B \times F_{i j}$ is the effect of the interaction between the $j$ th family and the $i$ th block, and $\varepsilon_{i j k}$ is the residual error. Blocks were considered as fixed effects. Family and $B \times F_{i j}$ interactions were considered random effects. Variance components of random effects were estimated using the average information REML algorithm implemented in the ASREML programme (GILMOUR et al., 1998). 
The individual tree heritability $\left(h^{2}{ }_{i}\right)$ was calculated for each trait, and was measured as:

$$
h_{i}^{2}=\sigma_{a}^{2} / \sigma_{P}^{2}
$$

where $\sigma_{a}^{2}$ represents the additive genetic variance and $\sigma_{p}^{2}$ represents the total phenotypic variance. Families in the progeny test were maternal half-siblings; therefore, the additive genetic variance $\left(\sigma_{a}^{2}\right)$ was estimated as 4 times the family component variance $\left(\sigma_{f}^{2}\right)$. Phenotypic variance was estimated as $\sigma_{p}^{2}=\sigma_{f}^{2}+\sigma_{f \times b}^{2}+\sigma_{\varepsilon}^{2}$. Standard errors for heritability were estimated by ASREML using a Taylor series approximation (GILMOUR et al., 1998).

Family heritability $\left(H^{2}\right)$ was calculated for each trait as follows:

$$
H^{2}=\frac{\sigma_{\mathrm{f}}^{2}}{\sigma_{f}^{2}+\sigma_{f \times b}^{2} / T+\sigma_{\varepsilon}^{2} / N T}
$$

where $T$ represents the number of blocks and $N$ represents the number of trees/family/block.

The genetic correlation $r_{G}$ between two traits measured was estimated as:

$$
r_{G}=\frac{\operatorname{cov}_{a}(x, y)}{\sqrt{\sigma_{a x}^{2} \cdot \sigma_{a y}^{2}}}
$$

where $\operatorname{cov}_{a}(x, y)$ is the additive genetic covariance between traits $x$ and $y, \sigma_{a x}^{2}$ is the additive genetic variance components for trait $x$, and $\sigma_{a y}^{2}$ is the additive genetic variance components for trait $y$. Standard errors and significance for genetic correlations were estimated via ASREML (GILMOUR et al., 1998).

\section{Results}

\subsection{Genetic variation of growth, stem form and wood basic density}

Table 1 shows that differences among families were highly significant for all traits $(P<0.05)$. The resin yield of the highest yielding family was 4 -fold greater than that of the lowest yielding family. The unimproved control family showed significantly lower resin yield than almost all families. The estimated heritability on a family mean basis was 0.47 for resin yield trait, which suggests that an important genetic gain for resin yield can be expected through a family selection in $P$. massoniana. Individual-tree heritability (0.38) was slightly lower than family heritability for resin yield.

For DBH, the average value was $11.72 \mathrm{~cm}$, with the variation ranging from $7.84 \mathrm{~cm}$ to $13.14 \mathrm{~cm}$ at the family level. The best growing family exceeded the slowest growing family (the control) by $67.6 \%$ for $\mathrm{DBH}$, showing the potential of $P$. massoniana for genetic improvement. For all analysed traits, the highest family heritability $\left(H^{2}=0.62\right)$ and individual-tree heritability $\left(h^{2}{ }_{i}=0.55\right)$ were estimated for $\mathrm{DBH}$, indicating that $\mathrm{DBH}$ is under strong genetic control. Comparatively, height and height under the live crown had only moderate individual tree heritabilities of 0.27 and 0.32 , respectively.

For crown size, the crown width was under weak to moderate genetic control with an individual heritability value of 0.17 and a family heritability value of 0.33 . This finding suggests that environmental factors greatly influenced crown width. In comparison, crown depth was under stronger genetic control $\left(H^{2}=0.61, h^{2}{ }_{i}=0.45\right)$.

Table 1. - Results of the mixed model for the fixed effects and variance components (\%) of the random effects and genetic parameter estimates. Significance levels: *** $P<0.001 ; * * P<0.01 ;$ and $* P<0.05$. OY $=$ resin yield,

\begin{tabular}{|c|c|c|c|c|c|c|c|c|}
\hline \multirow{2}{*}{ Trait } & \multirow{2}{*}{ Mean \pm S.D. } & \multirow{2}{*}{$\mathrm{CV}$} & \multirow{2}{*}{$\frac{\text { Fixed effect }}{\text { Block }}$} & \multicolumn{3}{|c|}{ Variance components (\%) } & \multirow{2}{*}{$H^{2}$} & \multirow{2}{*}{$h_{\mathrm{i}}^{2}(\mathrm{se})$} \\
\hline & & & & Family & Block $\times$ Family & Error & & \\
\hline $\mathrm{OY}(\mathrm{g})$ & $8.69 \pm 5.38$ & 61.91 & $* * *$ & $8.15^{* * *}$ & $17.00 * * *$ & 59.60 & 0.47 & $0.38(0.036)$ \\
\hline $\mathrm{DBH}(\mathrm{cm})$ & $11.72 \pm 1.72$ & 14.71 & $* * *$ & $12.67 * * *$ & 4.48 & 75.75 & 0.63 & $0.55(0.042)$ \\
\hline Height (m) & $7.60 \pm 0.94$ & 12.40 & $* * *$ & $5.67^{* * *}$ & 0.00 & 76.49 & 0.47 & $0.27(0.031)$ \\
\hline HLC (m) & $2.50 \pm 0.73$ & 29.24 & $* * *$ & $6.71^{* * *}$ & 0.00 & 76.49 & 0.51 & $0.32(0.033)$ \\
\hline $\mathrm{CW}(\mathrm{m})$ & $2.67 \pm 0.66$ & 24.82 & $* * *$ & $2.85^{*}$ & 1.36 & 64.01 & 0.33 & $0.17(0.027)$ \\
\hline $\mathrm{CD}(\mathrm{m})$ & $5.11 \pm 1.09$ & 21.42 & $* * *$ & $9.55^{* * *}$ & 0.00 & 74.63 & 0.61 & $0.45(0.038)$ \\
\hline NLW & $5.02 \pm 1.07$ & 21.40 & $* * *$ & $4.36^{*}$ & 0.00 & 89.02 & 0.37 & $0.19(0.028)$ \\
\hline NLB & $22.87 \pm 4.51$ & 19.74 & & $4.20 * *$ & 4.49 & 90.45 & 0.33 & $0.17(0.027)$ \\
\hline $\mathrm{BT}(\mathrm{mm})$ & $0.59 \pm 0.20$ & 34.67 & $* * *$ & $4.82 * *$ & 6.15 & 84.05 & 0.36 & $0.20(0.028)$ \\
\hline
\end{tabular}
$\mathrm{HLC}=$ height under live crown, $\mathrm{CW}=$ crown width, $\mathrm{CD}=$ crown depth, NLW = number of living whorls, NLB= number of living branchs, and BT= bark thickness. 
Table 2. - Genetic correlation (upper triangle, standard errors in parenthesis) and phenotypic correlation (lower triangle) of family means among different traits. Significance levels for correlation coefficients: *** $P<0.001$; ** $P<0.01$; and $* P<0.05$. - denote the value of correlation coefficient over 1.

\begin{tabular}{|c|c|c|c|c|c|c|c|c|c|}
\hline & DBH & Height & HLB & $\mathrm{CW}$ & $\mathrm{CL}$ & NLW & NLB & BT & OY \\
\hline \multirow{2}{*}{ DBH } & & $0.83^{* * *}$ & $-0.48^{* *}$ & $0.82^{* * *}$ & $0.76^{* * *}$ & 0.27 & $0.89^{* * *}$ & $0.60^{* * *}$ & $0.73^{* * *}$ \\
\hline & & $(0.07)$ & $(0.04)$ & $(0.09)$ & $(0.04)$ & $(0.07)$ & $(0.05)$ & $(0.05)$ & $(0.06)$ \\
\hline \multirow{2}{*}{ Height } & \multirow{2}{*}{$0.70^{* * *}$} & & $-0.46^{* *}$ & \multirow{2}{*}{-} & $0.86^{* * *}$ & $0.36^{*}$ & $0.75^{* * *}$ & -0.09 & $0.47 * *$ \\
\hline & & & $(0.05)$ & & $(0.02)$ & $(0.10)$ & $(0.04)$ & $(0.15)$ & $(0.04)$ \\
\hline \multirow{2}{*}{ HLC } & \multirow{2}{*}{$-0.31^{*}$} & \multirow{2}{*}{-0.16} & & $-0.36^{*}$ & $-0.85^{* * *}$ & $-0.99 * * *$ & $-0.59 * * *$ & $-0.61 * * *$ & $-0.45^{* *}$ \\
\hline & & & & $(0.06)$ & $(0.02)$ & $(0.03)$ & $(0.05)$ & $(0.04)$ & $(0.05)$ \\
\hline \multirow{2}{*}{$\mathrm{CW}$} & \multirow{2}{*}{$0.66^{* * *}$} & \multirow{2}{*}{$0.75^{* * *}$} & \multirow{2}{*}{-0.17} & & \multirow{2}{*}{-} & $0.63^{* * *}$ & & 0.17 & $0.56 * * *$ \\
\hline & & & & & & $(0.12)$ & - & $(0.13)$ & $(0.05)$ \\
\hline \multirow{2}{*}{$\mathrm{CD}$} & \multirow{2}{*}{$0.67^{* * *}$} & \multirow{2}{*}{$0.81 * * *$} & \multirow{2}{*}{$-0.71 * * *$} & \multirow{2}{*}{$0.63^{* * *}$} & & $0.79^{* * *}$ & $0.79^{* * *}$ & 0.27 & $0.54^{* * *}$ \\
\hline & & & & & & $(0.06)$ & $(0.03)$ & $(0.07)$ & $(0.03)$ \\
\hline \multirow{2}{*}{ NLW } & \multirow{2}{*}{0.26} & \multirow{2}{*}{$0.36^{*}$} & \multirow{2}{*}{$-0.65 * * *$} & \multirow{2}{*}{0.28} & \multirow{2}{*}{$0.66 * * *$} & & $0.82 * * *$ & -0.07 & $0.70^{* * *}$ \\
\hline & & & & & & & $(0.06)$ & $(0.07)$ & $(0.05)$ \\
\hline \multirow{2}{*}{ NLB } & \multirow{2}{*}{$0.66^{* * *}$} & \multirow{2}{*}{$0.59 * * *$} & \multirow{2}{*}{$-0.32 *$} & \multirow{2}{*}{$0.62^{* * *}$} & \multirow{2}{*}{$0.62 * * *$} & \multirow{2}{*}{$0.61^{* * *}$} & & $0.51^{* * *}$ & $0.99^{* * *}$ \\
\hline & & & & & & & & $(0.08)$ & $(0.07)$ \\
\hline \multirow{2}{*}{ BT } & \multirow{2}{*}{$0.58 * * *$} & \multirow{2}{*}{0.11} & \multirow{2}{*}{$-0.35^{*}$} & \multirow{2}{*}{0.24} & (2) & 000 & & & $0.57^{* * *}$ \\
\hline & & & & & 0.29 & 0.09 & $0.33^{*}$ & & $(0.07)$ \\
\hline OY & $0.36^{*}$ & 0.14 & -0.22 & 0.24 & 0.23 & 0.27 & $0.35^{*}$ & 0.24 & \\
\hline
\end{tabular}

Living whorl number, living branch number, and bark thickness had similar inheritance levels, with the family heritability values ranging from 0.33 to 0.36 , and the individual heritability values ranging from 0.17 to 0.20 .

\subsection{Genetic correlations between traits}

The phenotypic and genetic correlations between different traits are presented in Table 2. The data show that the genetic correlations for almost all traits were higher than the corresponding phenotypic correlations, which indicates that the use of phenotypic correlations to evaluate traits will result in the underestimation of potential gains from indirect selection, rather than genetic ones. The present study shows a moderate to high genetic correlation between different traits except for whorl number and bark thickness, which indicates that selection for one characteristic results in a simultaneous response of associated traits.

Resin ytield was more strongly genetic correlated with $\mathrm{DBH}\left(r_{g}=0.73\right)$ than with height $\left(r_{g}=0.47\right)$. The phenotypic and genetic correlations between $\mathrm{DBH}$ and resin yield were all significant $(P<0.05)$. Although the genetic correlation was also significant $(P<0.01)$, the phenotypic correlation of resin yield with height was only minimal (0.14).

Crown shape influences the light distribution pattern within the tree crown and may be viewed as an inherent characteristic of a species that reflects adaptation to the prevailing environment. In the present study, living branch number show the strongest positive genetic correlation with resin yield, with genetic correlation coefficients of $0.99 \pm 0.07$. These values indicated that these traits were probably controlled largely by the same set of genes. The genetic correlations between crown size (crown width and crown depth), bark thickness and resin yield were $0.56 \pm 0.05,0.54 \pm 0.03$, and $0.57 \pm 0.07$, respectively.

\section{Discussion}

The present study shows the important genetic variation in resin yield among $P$. massoniana families. The family heritabilities for resin yield were moderately high, which is consistent with the result for $P$. elliottii wherein the narrow-sense heritability of resin yield was 0.37 (PSWARAYI, 1996). However, the present estimate is lower than heritabilities reported for other pine species. For example, RoBERDs et al. (2003) reported that the individual narrow-sense heritabilities for spring flow and summer flow were 0.44 and 0.59 , respectively, in juvenile loblolly pine $(P$. taeda). SQUILLACE and BENGSTON (1961) estimated a narrow-sense heritability of around 0.55 for resin yield in P. elliottii. TADESSE et al. (2001) also indicated that the resin-yielding capability is under substantial genetic regulation in maritime pine (P. pinaster). Even so, the narrow-sense heritabilities for resin yield were moderate in the present study, and selections within the progeny tests can be further carried out to develop high-yielding resin genotypes. The 
relatively large genetic coefficients of variation also indicated high expected genetic gains. Resin is thought to be a primary means of defense by trees of the genus Pinus for resisting attack by bark beetles (LORIO et al., 1995; Medeiros and Vieira, 2008). Given that resin yield is under moderate to strong genetic control, the use of genetically improved materials could also increase the resistance of trees to bark beetle attack.

The estimated maximum value at the family level and mean for resin yield were both lower $(\max =11.81 \mathrm{~g}$, mean $=8.69 \mathrm{~g}$ ) than those derived by LIU (2005) in a previous study on $P$. massoniana $(\max =30.60 \mathrm{~g}$, mean $=18.35 \mathrm{~g}$ ) at 11 years old, but higher than the results $(\max =8.85 \mathrm{~g}$, mean $=7.22 \mathrm{~g})$ by ZENG (1998) for 48 families of $P$. massoniana 7 years to 13 years old). The difference in resin yield between this study and the two aforementioned trials may be due to differences in the age of the material being compared. LIU (2005) pointed out that resin yield increased with age.

Selection of plus trees according to resin yield may lead to biased population for $\mathrm{DBH}$ and height. Comparing the mean annual growth rate estimated over all families $(\mathrm{DBH}=1.46 \mathrm{~cm}$, height $=0.95 \mathrm{~m})$ with that observed by YANG et al. (2003) $(\mathrm{DBH}=1.25 \mathrm{~cm}$, height $=0.99 \mathrm{~m}$ ) in the same species (9 years old for average growth of open-pollinated progeny tests) in Sanming, Fujian, China, and with that by JI et al. (2005) $(\mathrm{DBH}=1.27 \mathrm{~cm}$, height $=0.98 \mathrm{~m})$ for 8-year-old open-pollinated progenies of $P$. massoniana in Zhangping, Fujian, China. Therefore, this progeny test has good performance for DBH and height, and selection for resin yield did not have a negative effect on growth.

Many studies have proven that $\mathrm{DBH}$ and height growth are under substantial genetic control for coniferous species. JIN et al. (2008) obtained family heritability values for the $\mathrm{DBH}$ of $P$. massoniana ranging between 0.66 and 0.91 , and from 0.56 to 0.88 for height. In P. elliottii, ZHANG et al. (2010) also reported that individual-tree heritability values for $\mathrm{DBH}$ and height were 0.60 and 0.43 , respectively. WENG et al. (2007) estimated that the narrow-sense heritability of height was around 0.25 at age 7 for Jack pine, and $h^{2}{ }_{i}$ estimates for height increased with age. However, some researchers support the viewpoint that growth traits $(\mathrm{DBH})$ frequently exhibit relatively low values of heritability (HARFOUCHE et al., 1995). As to the heritability for DBH and height, SEBBENN et al. (2006) also reported that the estimates of heritability were higher for DBH $\left(H^{2}=0.56, h^{2}{ }_{i}=0.19\right)$ than for height $\left(H^{2}=0.24, h^{2}{ }_{i}=0.07\right)$ at the family and individual levels for 15-year-old $P$. caribaea. These findings are similar with the present results, which indicate that $\mathrm{DBH}$ has higher genetic control than height and more genetic gain in terms of tree volume can be expected from the selection for $\mathrm{DBH}$ than for height.

In the present study, the family heritability estimate for crown width was slightly higher than for the same variable at 8 years $\left(H^{2}=0.22\right)$ reported by JI et al. (2005) form a half-sibling $P$. massoniana test, but was similar to the individual heritability estimate $\left(h^{2}{ }_{i}=0.23\right)$ for grown width in 3-year-old loblolly pine (YU, 2000). The estimates for living branch numbers were in general agreement with the heritabilities reported by IsIK et al. (1999) $\left(H^{2}=0.19\right.$ and $0.44, h^{2}{ }_{i}=0.10$ and 0.33$)$ for P. brutia at ages 13 and 17 years. For bark thickness, similar results were observed in a previous study on $P$. brutia (IsIK et al., 1999), wherein the bark thickness at breast height showed moderate heritabilities $\left(h^{2}{ }_{i}=0.17\right)$ at age 13. For living whorl number, less information regarding the inheritance is available. The above results indicate that most variation is due to environmental factors not to genetic factors, limiting achievable gains from selection.

Previous works on $P$. massoniana have reported that the correlation between resin yield and growth traits (DBH and height) presents a positive phenotypic correlation (CAI et al., 2006; QIN et al., 2005). SQUILLACE (1965) proposed that both resin yield and growth rate are genetically correlated to at least a moderate degree in $P$. elliottii. Similar results were obtained in the same species by ZHANG et al. (2010). RoBERDs et al. (2003) and BLANCHE et al. (1992) have also studied loblolly pine, and have observed that higher and moderate genetic correlations occur between resin yield and growth traits. This finding indicates that genetic factors act concurrently to increase resin yield and growth.

The relationship between resin yield and growth in pines has been explained by SQuILLACE (1965) in terms of pleiotropy, which causes the positive association between growth and resin yield in slash pine. A genetic improvement in resin yield is also proposed to cause simultaneous improvement in growth. The relationship between resin yield and growth in pines has been also explained by LORIO (1986) using the growth-differentiation balance hypothesis. Supposedly, a tradeoff occurs between growth and resin yield as determined by the allocation of photosynthates to primary and secondary metabolic processes. The acquired resource is limiting; thus, the relationship of growth with resin yield is expected to be negative. However, positive correlations are possible between traits influenced by the resource allocation trade-off. NoORDWIJK and JONG (1986) suggested an acquisition-allocation dichotomy to explain phenotypic correlations, which depend on the relative variations in the acquisition and allocation of resources. When resource acquisition ability is considerably greater than variation in the allocation of resources, a positive correlation can be obtained. The elements of this basic idea have been adopted by Houle (1991), who has reported the relative numbers of loci that affect either acquisitions or allocations, but not both, play a role in acquiring versus allocating a limiting resource for determining genetic correlation. If the number of loci involved in acquiring a resource exceeds the number of loci involved in resource allocation, positive genetic correlations between traits are possible. Recent studies (ZHANG et al., 2010; RoBERDs et al., 2003) show that combining high resin yield with other desirable traits such as rapid growth, straight stems, and small branch size is feasible.

Previous works have reported that the crown size of trees can influence resin yield (COPPEN and HONE, 1995). KARKI and TIGERSTEDT (1985) proposed that trees with 
long narrow crowns and relatively few but thin short branches borne at acute angles could produce both high yields and stem wood allocation percentages. PSWARAYI (1996) has demonstrated that in P. elliottii, the genetic correlation between branch number and resin yield is low (0.21) but positive. Slightly higher correlation coefficients have been obtained by ZHAO and SHI (1984) in P. massoniana, wherein the phenotypic correlation between crown width, crown depth, branch number, bark thickness, and resin yield ranged from 0.30 to 0.38 . Although a positive correlation was observed among crown width, bark thickness, and resin yield in P. massoniana, CHEN (2007) proposed that bark thickness has the most influence on resin yield $\left(r_{p}=0.7\right)$ among ditch burden rate, crown width, and bark thickness. The present estimated genetic correlations between crown shape traits, bark thickness, and resin yield were moderate to strong. That is, a tree with a larger crown size, more living whorls and branches, and thicker bark usually produces more resin. Therefore, crown shape and bark thickness, especially living branch number, could also be used as indirect assisted traits for selecting highyielding trees. However, these traits have lower heritability estimates or genetic correlations with resin yield than the $\mathrm{DBH}$ trait. Thus, $\mathrm{DBH}$ is believed to be the optimum assisted trait for indirectly selecting highyielding resin trees.

\section{Acknowledgments}

The authors thank the senior engineer of WENRONG CHEN and QIAONV CHEN from Laizhou forest farm in Nanping City of Fujian, for support in the field work. We would also thank the invaluable help of the reviewers to improve the manuscript.

\section{Funding}

The present research was funded by the National Forestry Public Welfare Program of China (Grant no. 201104020), the National Natural Science Foundation of China (Grant no. 31100491) and National Science \& Technology Pillar Program in the 11th Five year Plan of china (Grant no. 2012BAD01B02).

\section{Reference}

Blanche, C. A., P. L. Lorio Jr., R. A. Sommers, J. D. Hodges and T. E. NebeKer (1992): Seasonal cambial growth and development of loblolly pine: xylem formation, inner bark chemistry, resin ducts, and resin flow. For Ecol Manage 49: 151-165.

CAI, S.W., W. LONG and Z. Q. YANG (2006): Study on the relationship of oleoresin yield and tree factor of different provenances of $P$. massoniana. Guangxi Forestry Science 35: 18-19.

Chen, J. Q., Y. S. Su, X. S. Huang and Y. P. Huang (2004): Research on effects of mixed rosin on disproportion. Journal of Chemical Industry of Forest Products 38: $1-4$.

Coppen, J. J. and G. A. Hone (1995): Gum Naval Stores: Turpentine and Rosin from Pine Resin. Non-Wood Forest Products 2. Natural Resources Institute, FAO, Rome.
Gilmour, A., B. Gogel, B. Cullis, S. Welham and R. Thompson (1998): ASREML Users Manual, VSN International. New south Wales Agriculture, Orange.

Goddard, R. E. and W. J. Peters (1965): Progress in the selection and breeding of superior trees to upgrade gum yield. Naval Stores Rev. 74: 4-5, 13, 15.

Harfouche, A., P. Baradat and C. Durel (1995): Intraspecific variability in Maritime pine (Pinus pinaster Ait.) in the South-East of France. 1. Variability in autochthonous populations nd in the whole range of species. Ann For. Sci. 52: 307-328.

Houle, D. (1991): Genetic covariance of fitness correlates: what genetic correlations are made of and why it matters. Evolution 45: 630-648.

IsIK, K. and F. IsIK (1999): Genetic variation in Pinus brutia Ten. In Turkey: II. Branching and Crown Traits. Silvae Genetica 48: 293-302.

JI, K. S., M. L. FAN and L. A. XU (2005): Variation analysis and plus family selection on half-Sib progenies from clonal seed orchard of Pinus massoniana. Scientia Silvae Sinicae 41: 43-49.

JIN, G. Q., G. F. QIN, W. H. LIU, D. Y. CHU, S. Z. Hong and Z. C. ZHOU (2008): Genetic analysis of growth traits on tester strain progeny of Pinus massoniana. Scientia Silvae Sinicae 44: 70-76.

Karki, L. and P. M. A. Tigerstedt (1985): Definition and exploitation of forest tree ideotypes in Finland. In: CAnnell, M. G. R., JACKsON, J. E. (Eds.), Attributes of Trees As Crop Plants. Institute of Terrestrial Ecology. 102-109.

Kelkar, V. M., B.W. Geils, D. R. Becker, S. T. Overby and D. G. NeARY (2006): How to recover more value from small pine trees: essential oils and resins. Biomass Bioenerg 30: 316-320. doi: 10.1016/j.biombioe.2005. 07.009

LeE, H. J., M. M. RAVN and R. M. CoATES (2001): Synthesis and characterization of abietadiene, levopimaradiene, palustradiene, and neoabietadiene: hydrocarbon precursors of the abietane diterpene resin acids. Tetrahedron 57: 6155-6177.

LI, S. G., Y. P. FU, K. F. Zhang, Y. D. JianG, Z. Q. YAO and M. LI (2008): Half-sib progeny tests of high-resin-yielding Pinus kesiya var. langbianensis. Journal of Zhejiang Forestry College 25: 158-162.

LIU, Y. R. (2005): Determination of the rosin-producing capacity of the open pollination progeny stand from the plus trees in high-yield rosin Pinus massoniana forest. Journal of Fujian College of Forestry 25: 229-233.

LiU, Y. R. (2006): Selection of high -resin-yield half-sib Pinus massoniana single tree with superior resin-producing capacity. Forestry Science and Technology 31: $1-4$.

LORIO, P. L. JR. (1986): Growth-differentiation balance: a basis for understanding southern pine beetle-tree interactions. For Ecol Manage 14: 259-273.

Lorio, P. L. JR., E. M. Stephen and T. D. PAine (1995): Environment and ontogeny modify loblolly pine response to induced acute water deficits and bark beetle attack. For Ecol Manage 73: 97-101.

McReynolds, R. D. and C. R. GANSEL (1985): High-gumyielding slash pine: Performance to age 30 . South J Appl For 9: 29-32.

Medeiros, R. S. G. and Vieira (2008): Sustainability of extraction and production of copaiba (Copaifera multijuga Hayne) oleoresin in Manaus, Am, Brazil. For Ecol Manag 256: 282-288. 